\title{
Survey of knowledge for diagnosing and managing prediabetes in Latin-America: cross-sectional study
}

\author{
Jennifer Garay', Paul A. Camacho1,2, Jose Lopez-Lopez' , Juliana Alvernia1', Marcela Garcia', Daniel D. Cohen 1,3, \\ Carlos Calderon ${ }^{5}$ and Patricio Lopez-Jaramillo $1,2,3,4^{*}$
}

\begin{abstract}
Background: Prediabetes has been proposed as a risk factor for the development of type 2 diabetes mellitus (DM2) and cardiovascular disease (CVD). Despite the clinical importance of prediabetes, little is known about the level of knowledge, beliefs and barriers to screening and treating prediabetes amongst care health providers in Latin America. The aim of the present survey was to evaluate the knowledge and beliefs about prediabetes amongst in Latin American health care providers.

Methodology: In a cross-sectional study, we adapted the written survey designed by the Johns Hopkins University group, and applied it to health care providers across Latin America during three meetings, in 2017, and with physicians from primary care centers in Bucaramanga, Colombia convened in 2017. The survey consisted of questions under four headings, diabetes screening, management of prediabetes, pharmacological treatment-metformin use, and demographic information. We perform a descriptive analysis to determine the differences in responses between different medical specialties.

Results: The majority of the care providers that answered the survey were Colombian physicians, $54.5 \%$ of respondents had 10 years or more since completing their training and more women responded. Only $9.5 \%$ identified the 12 prediabetes risk factors described in the literature. The most common risk factor identified was a family history of diabetes, followed by overweight, a sedentary lifestyle and dyslipidemia, while ethnicity was the risk factor least commonly. $47.1 \%$ answered that laboratory tests to detect prediabetes are fasting glucose and $\mathrm{HbA1C}, 82.5 \%$ correctly identified fasting plasma glucose as the best test, $35.9 \%$ correctly responded that to the recommended weight loss goal is 5 to $7 \%$ and $49.1 \%$ that 150 min is considered the minimum level of physical activity per week. $78 \%$ agreed that the identification and treatment of prediabetes is important. $56 \%$ believed that patients with prediabetes progress more rapidly to diabetes and $40.6 \%$ considered that metformin could reduce the risk of diabetes in patients already diagnosed with prediabetes.
\end{abstract}

Conclusion: These results demonstrate that there are important gaps in the knowledge of the diagnosis, clinical implications and management of prediabetes amongst Latin America health providers.

Keywords: Latin America, Prediabetes, Knowledge, Diagnosis, Management

*Correspondence: jplopezj@gmail.com

${ }^{1}$ Research Department, Fundacion Oftalmologica de Santander (FOSCAL) Internacional, Calle 158 \# 20-95, Consultorio 101/102, Floridablanca,

Santander, Colombia

Full list of author information is available at the end of the article

\section{Background}

Prediabetes, as defined by the American Diabetes Association guidelines, is the term used for those individuals who's glucose levels do not meet the criteria for diabetes but are sufficiently elevated to increase the risk of cardiovascular disease (CVD) [1]. Although it is not a distinct clinical entity, prediabetes increases the risk of 
developing diabetes mellitus 2 (DM2) 3-10 times and is associated with a progress towards DM2 of $10 \%$ annually $[2,3]$. Prediabetes includes impaired fasting glucose (IFG) and/or impaired glucose tolerance (IGT) [4]. In 2015 it was estimated that 84.1 million people had prediabetes, but only $11.6 \%$ of these people had been informed of this by a health provider $[5,6]$. The International Diabetes Federation (IDF) estimates that globally there are 280 million people with IGT [6]. The prevalence of prediabetes in Latin America is reported to be 9.8\% [7] and in this population, prediabetes was shown to be the most frequent glucose disorder in patients with acute myocardial infarction (AMI) [8]. In the United States of America (USA), despite the clinical importance of prediabetes, knowledge of the condition and its detection and treatment is very low amongst primary health care providers [7], and it is relatively unknown in Latin America. Therefore, the objective of this survey was to assess the state of knowledge and beliefs about prediabetes among health care providers in Latin America and differentiate between the specialties.

\section{Methods}

This is a cross-sectional study in which a written survey designed by the Johns Hopkins University group [9] was adapted and translated it into Spanish. The survey uses the American Diabetes Association (ADA) criteria for the diagnosis of prediabetes and includes questions about the management, practices, attitudes, and beliefs in prediabetes [10]. The survey comprises four components. Questions in the first section are about diabetes screening, including knowledge about risk factors, methods, and guidelines for screening. The second section asks about the management of prediabetes, including initial therapy, drug therapy, and follow-up. The third contains specific questions about pharmacological treatment, including the prescription of metformin and barriers about its use. The final part includes demographic information, type of medical specialty, training time, and consultation time per week. The survey was distributed and completed by health care providers during the $\mathrm{X}$ LatinoAmerican Internal Medicine meeting/XXVI Colombian Internal Medicine Association/American College Physicians meeting, Cartagena, and the 84th diabetes update Course from the Colombian Diabetes Federation, Barranquilla, and the Third Central American Diabetic Foot Congress at Tegucigalpa, Honduras, all occurring during August 2017. At the same time, the survey was also delivered to physicians in the health centers of the Institute of Health of Bucaramanga, Colombia (ISABU). Survey data was entered into a web portal. As local regulations state that this kind of observational studies do not require ethical clearance, the survey was not submitted to an ethical committee.

\section{Statistical analysis}

We perform a descriptive analysis. Qualitative variables were summarized in absolute and relative frequencies. The quantitative variables were summarized with measures of central tendency, position and dispersion according to the frequency distribution. The difference in the results of the study were estimated using the Chi-square test and the exact Fischer test. For questions using a Likert scale, we dichotomized the answers to agree; by combining agree and, strongly agree and disagree; by combining neutral, disagree and strongly disagree. All statistical analysis was carried out using statistical software Stata, version 11.0 (Stata Corporation, College Station, TX, USA). The level of significance of the study is $5 \%$.

\section{Results}

The majority of the care providers that responded to the survey were physicians (94.3\%), and 5.7\% were nurses, nutritionist and physical therapists (Table 1). $42.1 \%$ had 10 years or more since completing their training. There were more females (53.7\%) than males. Table 1 summarizes the characteristics of survey respondents.

\section{Table 1 Characteristics of survey respondents $(n=373)$}

\begin{tabular}{ll}
\hline Provider characteristics & N (\%) \\
\hline Specialty & \\
General medicine & $189(60.2)$ \\
Specialty medicine & $107(34.1)$ \\
$\quad$ Internal medicine & 87 \\
Family medicine & 11 \\
$\quad$ Other specialties & 9 \\
Others & $18(5.7)$ \\
Provider type & \\
Physicians & $296(94.3)$ \\
Nurse & $12(3.8)$ \\
Nutritionist & $5(1.6)$ \\
Physical conditioner & $1(0.3)$ \\
Number of years since completing training & a \\
<5 years & $112(42.4)$ \\
$5-10$ years & $41(15.5)$ \\
10+ years & $111(42.1)$ \\
Gender & \\
Female & $174(53.7)$ \\
Male & $150(46.3)$
\end{tabular}

10 Missing

a 40 Missing 
Table 2 Knowledge for diagnoses criteria and management of prediabetes

\begin{tabular}{|c|c|c|}
\hline & $\mathrm{N}(\%)$ & P value \\
\hline Correct identification of diabetes laboratory criteria; fasting glucose & $275(83.3)$ & 0.001 \\
\hline Correct identification of diabetes laboratory criteria; HbA1c & $192(58.2)$ & 0.055 \\
\hline Correct identification of prediabetes laboratory criteria; fasting glucose & $168(48.2)$ & 0.349 \\
\hline Correct identification of prediabetes laboratory criteria; HbA1c & $49(15.1)$ & 0.481 \\
\hline Correct body weight loss recommendation; $5-7 \%$ & $107(35.1)$ & 0.172 \\
\hline Correct physical activity recommendation; 150 min/week & $167(51.7)$ & 0.391 \\
\hline Correct initial management recommendation; referral to behavioral weight loss program & $7(3.03)$ & 0.519 \\
\hline
\end{tabular}

\section{Knowledge of risk factors and laboratory criteria, prediabetes practice and management}

Table 2 summaries knowledge of diagnoses criteria and management of prediabetes. The principle approaches for initial management of prediabetes used by the providers were: counseling on diet changes and physical activity to lose weight (94.9\%), and referral of the patient to a nutritionist (57.3\%). Seventy percent considered that they should repeat laboratory tests 3 months after the diagnosis of prediabetes with further follow up 3 months after that (75.1). Almost $80 \%$ of the physicians that had patients with prediabetes (without progression to diabetes) had prescribed less than $25 \%$ with metformin. Table 3 shows self-reported practice in patients with prediabetes.

\section{Attitudes, beliefs and barriers}

There is strong agreement (78\%) that the identification and management of prediabetes is important, but just $46 \%$ strongly agreed that this would help identify the means to treat comorbidities like hypertension, and only $56 \%$ believed that patients with prediabetes progress more rapidly to diabetes. Only $40.6 \%$ considered that metformin could reduce the risk of diabetes in patients that have already been diagnosed with prediabetes.

Amongst the barriers that the providers identified to be effective in lifestyle changes, (88.4\%) agreed and strongly agreed that there was a lack of patient motivation, $(72.5 \%)$ thought that the patients did not consider lifestyle changes important. $45 \%$ considered that weightloss and physical activity goals were not achieved due to lack of resources, or to financial limitations. Table 4 summarizes the barriers for interventions in prediabetes patients.

Amongst the interventions that could be improved in the management and treatment of prediabetes, (92.4\%) believed that there is a need to improve the access to prevention programs and $58 \%$ believed that there is a need for more, and better, educational and nutritional resources. The reasons providers gave for prescribing metformin in patients with prediabetes were: risk of diabetes and obesity (73\%), HbA1c > 6\% (53\%), lack of response to lifestyle intervention (52\%) and family history of diabetes (47\%). Providers agreed and strongly agreed that the main barriers to the use of metformin is poor patient adherence (76.2\%) and because patients did not like to take medicines (70.8\%). Moreover, the lack of awareness about the recommendations of the clinical guidelines for metformin use in prediabetes is high (61.4\%).

Table 3 Self-reported practice in prediabetes patients

\begin{tabular}{|c|c|c|}
\hline Practice & $\mathrm{N}(\%)$ current study & $P$ value \\
\hline \multicolumn{3}{|l|}{ Initial management approach } \\
\hline $\begin{array}{l}\text { Counseling on diet changes and physi- } \\
\text { cal activity }\end{array}$ & $313(94.9)$ & 0.063 \\
\hline Refer to nutritionist & $189(57.3)$ & 0.002 \\
\hline $\begin{array}{l}\text { Refer to behavioral weight loss } \\
\text { program }\end{array}$ & $98(29.7)$ & 0.132 \\
\hline Discuss starting metformin & $102(30.9)$ & 0.832 \\
\hline Refer for bariatric surgery & $10(3.0)$ & 0.934 \\
\hline \multicolumn{3}{|l|}{ Repeat laboratory tests } \\
\hline 3 months & $233(70.8)$ & $<0.001$ \\
\hline 6 months & $62(18.8)$ & 0.001 \\
\hline 1 year & $23(7.0)$ & 0.754 \\
\hline 2 years & $2(0.6)$ & - \\
\hline No specific recommendation & $9(2.8)$ & 0.900 \\
\hline \multicolumn{3}{|l|}{ Return for follow-up clinic visit } \\
\hline 3 months & $247(75.1)$ & $<0.001$ \\
\hline 6 months & $45(13.7)$ & 0.004 \\
\hline 1 year & $16(4.9)$ & 0.992 \\
\hline 2 years & $1(0.3)$ & - \\
\hline No specific recommendation & $1(0.3)$ & - \\
\hline \multicolumn{3}{|c|}{$\%$ Patients with prediabetes prescribed metformin } \\
\hline $0 \%$ & $72(21.9)$ & 0.766 \\
\hline $1-5 \%$ & $93(28.3)$ & 0.343 \\
\hline$>5-25 \%$ & $76(23.1)$ & 0.746 \\
\hline$>25-50 \%$ & $41(12.5)$ & 0.586 \\
\hline$>50-75 \%$ & $29(8.8)$ & 0.784 \\
\hline$>75 \%$ & $18(5.5)$ & 0.809 \\
\hline
\end{tabular}




\section{Knowledge by type of speciality of the provider}

There was no difference in the level of knowledge about the risk factors that might prompt screening for prediabetes and diabetes between doctors in general medicine, internal medicine, other specialties and other health providers. Similarly, there were no differences in the laboratory criteria for diagnosing prediabetes with the use of $\mathrm{HbA1c}$, in the minimum weight loss recommendation or the selection of laboratory tests for screening. However, there were differences in the correct identification of recommended minimum physical activity and in the fasting glucose values that diagnosed prediabetes (Fig. 1).

\section{Discussion}

The present study shows that there is insufficient knowledge about the diagnosis, clinical implications and management of prediabetes amongst the Latin American health providers. The participants answered correctly that a family history of diabetes in a first-degree relative is a main risk factor and the main criteria to screen their patients. However, few recognized ethnicity as a risk factor or that prediabetes is a risk factor for CVD. Despite $75 \%$ of those surveyed agreeing that lifestyle modification can reduce the risk of diabetes, $50 \%$ correctly identified guidelines recommendations for minimum physical activity and target weight-loss [1]. There was a strong perception that low adherence of patients to lifestyle modifications is due to the lack of motivation and a perception that these changes have clinical impact. However, there is also a lack of familiarity with weight loss programs and skepticism about the effectiveness of these programs among health care providers [11-13]. There is an important substantial underprescription of metformin in the treatment of prediabetes, despite the published Latin American and Colombian Consensus recommending its use if the goal of glycemia is not achieved after 3 months of lifestyle changes [1, 3, 14]. Additionally, the ADA guidelines [1] recommend the use of metformin for the prevention of development of DM2 in subjects with prediabetes, especially in those with body mass index $>35 \mathrm{~kg} / \mathrm{m}^{2}$, over 60 years old, and in women with a history of gestational diabetes (recommendation grade A). This recommendation is based mainly on the results of the Diabetes Prevention Program [15, 16], which showed the importance of using metformin in high-risk subjects. Of the 3234 subjects with IFG and body mass index $(\mathrm{BMI})>24$ included in the study, 1079 were randomized to intensive lifestyle intervention, 924 to metformin treatment, and 932 to placebo. At 2.8 years of follow-up, lifestyle changes were the most effective intervention for the reduction in the incidence of DM2 (58\% compared to placebo). However, metformin was effective in reducing this incidence by $31 \%$ compared to the placebo. Moreover, at the 15-year follow-up, the incidence

Table 4 Barriers for interventions in prediabetes patients

\begin{tabular}{|c|c|c|}
\hline & $\mathrm{N}(\%)$ & $P$ value \\
\hline \multicolumn{3}{|l|}{ Barriers to lifestyle modification (strongly agree and agree) } \\
\hline Patient's lack of motivation & $290(88.4)$ & 0.488 \\
\hline Patient's physical limitation in doing activity & $200(61.7)$ & 0.040 \\
\hline Lack of weight loss resources for patient & $148(45.3)$ & 0.003 \\
\hline Lack nutrition resources for patient & $176(53.7)$ & 0.006 \\
\hline Patients do not think it is important to make these changes & $235(72.5)$ & 0.404 \\
\hline Financial limitations & $161(49.2)$ & 0.346 \\
\hline \multicolumn{3}{|l|}{ Barriers to metformin use (strongly agree and agree) } \\
\hline Patients dislike taking medications & $228(70.8)$ & 0.001 \\
\hline Medication cost to patient & $108(33.4)$ & 0.188 \\
\hline Poor patient adherence & $246(76.2)$ & 0.232 \\
\hline Potential side effects & $188(58.6)$ & 0.001 \\
\hline Providers' lack of awareness of clinical guidelines for metformin use & $197(61.4)$ & 0.270 \\
\hline Lack of FDA approval for metformin use in prediabetes & $97(30.8)$ & 0.878 \\
\hline \multicolumn{3}{|c|}{ Interventions to improve management of prediabetes (strongly agree and agree) } \\
\hline More time for doctors to counsel patients & $275(83.8)$ & 0.768 \\
\hline More educational resources for patients & $291(88.7)$ & 0.816 \\
\hline Improved access to diabetes preventive programs & $302(92.4)$ & 0.199 \\
\hline Improved nutrition resources for patients & $278(84.8)$ & 0.006 \\
\hline Improved access to weight loss programs & $282(86.5)$ & 0.229 \\
\hline Improved access to bariatric surgery & $103(31.6)$ & 0.613 \\
\hline
\end{tabular}




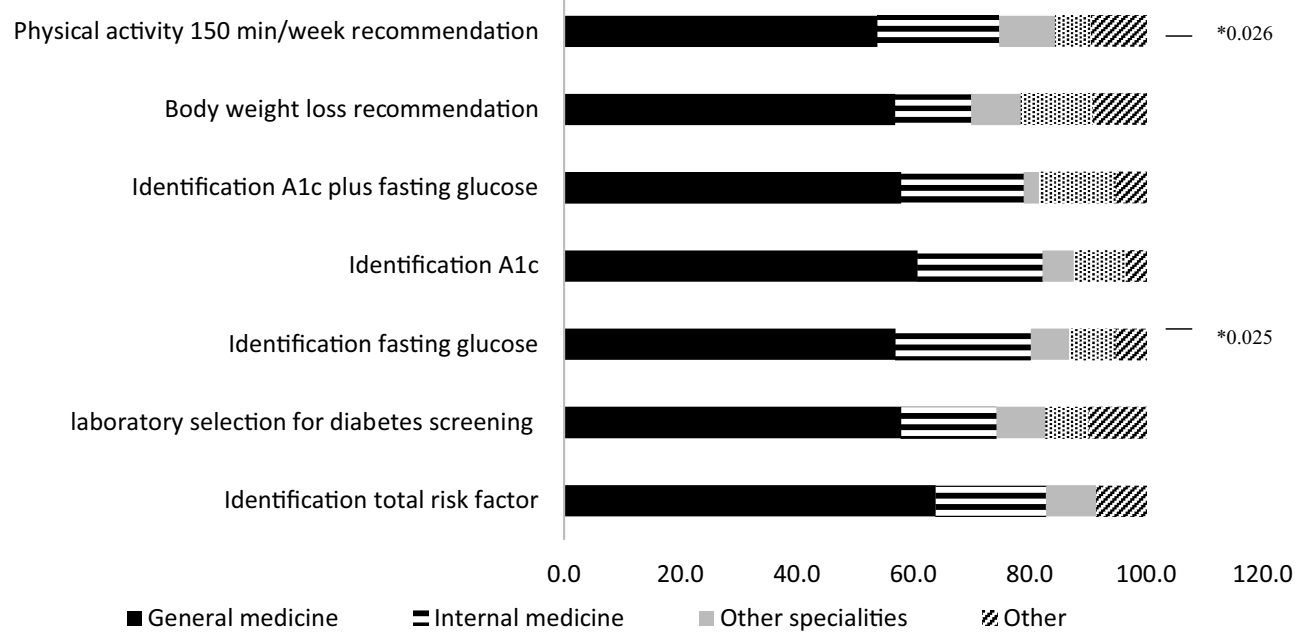

Fig. 1 Correct identification of the diagnosis criteria and recommendations for prediabetes: a comparison between health providers

of diabetes was reduced by $18 \%$ in the metformin group (0.82, 0.72-0.93; $\mathrm{p}=0.001)$ compared to placebo [17]. Lifestyle changes are the first line and the cornerstone of dysglycemia management. However, given the particular context of our region regarding social and economic, where there are limited time and resources to implement adequate monitoring programs, the addition of the pharmacological strategy as a compliment in the management could be a correct intervention. In addition, the Diabetes Prevention Program of India (IDPP) that resemblances our socioeconomic context showed that changes in lifestyle and metformin reduced the progression to DM2 in a similar proportion, $28.5 \%$ (95\% CI 20.5 to $37.3 \%$ ) vs $26.4 \%$ (95\% CI 19.1 to $35.1 \%$ ), respectively [18]. The results of our study are worrisome since we have previously shown that $49 \%$ of patients with a first AMI were unaware that they had prediabetes, which is not only associated with a higher risk of AMI, but also to lower survival rates following it [8]. Moreover, there is evidence that the benefit of treating prediabetes is the reduction in the risk of progression to diabetes and coronary atherosclerosis [18-20].

The general medicine physicians, who in Latin America are the first line or gatekeeper of primary care provision $[21,22]$, had the best survey performance in comparison with the internal medicine and other specialists. This is an unexpected result, which may be related to the fact that many of the general medicine physician's surveyed work in direct government preventive care programs. Nonetheless, the overall knowledge of detection and management of prediabetes can be considered too low as previously reported in health providers in a region of the USA [9]. The adoption of the guidelines proposed by the World Health Organization (WHO), including the " $25 \times 25$ " strategy, can improve the detection and control of the main cardiovascular risk factors [23]. For example, the Heart Outcomes Prevention Evaluation 4 (HOPE-4) [24], community-based implementation study showed that task-sharing with non-physician health workers for the education of patients, the supply of free medicines, and the participation of family and friends led to a more than $40 \%$ reduction in estimated cardiovascular risk at 10 years and doubled the control of hypertension in comparison to the control group (usual medical care). This strategy could be adapted for the early recognition of prediabetes and its management at the community and primary care health providers level.

The present study has some limitations. The survey was not validated; however, due to the characteristics of the people evaluated, the questions were designed to evaluate concepts about universal definitions. Most of the participants surveyed were physicians, dissimilar to the percentage of nurses included in the survey that was low because of the low attendance rates of this group to the events. These events were predominantly directed to physicians. There was a lack of complementary questions such as around the knowledge of the glucose tolerance test. However, this is also a limitation of the original survey. The providers surveyed attended to three different medical meetings which included prediabetes related topics and were completed during the sessions, this may lead to a higher risk of information bias. We therefore need to survey a sample in a different context to determine the reproducibility of our results, particularly considering that our sample was not representative of Latin America as a whole, with as most participants were from Colombia. 


\section{Conclusions}

Our results demonstrate important gaps in the knowledge of the diagnosis, clinical implications and management of prediabetes amongst the Latin America health providers. These results are of concern since in recent decades there has been a substantial increase in the prediabetes burden in Latin America, associated with an increased risk of DM2 and CVD [3, 7]. Moreover, there is evidence that early identification and management of prediabetes may prevent or delay the progression to diabetes and cardiovascular events [18-20]. Our results suggest that there is an urgent need to widely implement and improve the teaching of prediabetes in medical and health schools and in continuing medical education programs.

\section{Abbreviations \\ DM2: diabetes mellitus type 2; HbA1C: glycosylated hemoglobin; IFG: fasting impaired glucose; IGT: impaired glucose tolerance; CVD: cardiovascular dis- ease; IDF: International Diabetes Federation; AMI: acute myocardial infarction; USA: United States of America; ADA: American Diabetes Association; ISABU: Institute of Health of Bucaramanga.}

\section{Acknowledgements}

To all the health workers that answer the survey.

\section{Authors' contributions}

JG, DC and PL-J conceive and design the survey. JG, DC and CC applied the survey. PC did the statistical analysis. MG and JA elaborate the first draft manuscript. JL-L has elaborated this revised version. All authors read and approved the final manuscript.

\section{Funding}

FOSCAL and FUSANDE provide resources to implement the survey.

\section{Availability of data and materials}

The author of correspondence has available the total data.

\section{Ethics approval and consent to participate}

Not applicable.

\section{Consent for publication}

Not applicable.

\section{Competing interests}

The authors declare that they have no competing interests.

\section{Author details}

${ }^{1}$ Research Department, Fundacion Oftalmologica de Santander (FOSCAL) Internacional, Calle 158 \# 20-95, Consultorio 101/102, Floridablanca, Santander, Colombia. ${ }^{2}$ Medical School, Universidad Autónoma de Bucaramanga (UNAB), Floridablanca, Colombia. ${ }^{3}$ Instituto Masira, Medical School, Universidad de Santander (UDES), Bucaramanga, Colombia. ${ }^{4}$ Eugenio Espejo Medical School, Universidad UTE, Quito, Ecuador. ${ }^{5}$ Fundación Santandereana de Diabetes (FUSANDE), Cra. 33 \#46-45, Bucaramanga, Santander, Colombia.

Received: 29 August 2019 Accepted: 28 November 2019

Published online: 04 December 2019

\section{References}

1. American Diabetes Association. Standards of medical care in diabetes-2018. Diabetes Care. 2018;41(Suppl 1):S1-2. https://doi.org/10.2337/ dc18-SINT01.
2. Huang Y, Cai X, Mai W, Li M, Hu Y. Association between prediabetes and risk of cardiovascular disease and all cause mortality systematic review and meta-analysis. BMJ. 2016;355:15953. https://doi.org/10.1136/bmj. i5953.

3. López-Jaramillo P, Nieto-Martínez RE, Aure-Fariñez G, Mendivil CO, Lahsen RA, Silva-Filho RL, et al. Identification and management of prediabetes: results of the Latin America strategic prediabetes meeting. Rev Panam Salud Publica. 2017;41:e172. https://doi.org/10.26633/RPSP.2017.172.

4. WHO. Definition and diagnosis of diabetes mellitus and intermediate hyperglycemia. Geneva: World Health Organization; 2006. p. 1-38.

5. Centers for Disease Control and Prevention. National diabetes statistics report: Estimates of diabetes and its burden in the United States. Centers for Disease Control and Prevention national diabetes statistics report. Atlanta: U.S. Department of Health and Human Services; 2017. p. 1-20.

6. Cho NH, Whiting D, Forouhi N, Guariguata L, Hambleton I, Li R, International Diabetes Federation, et al. IDF Diabetes Atlas. 7th ed. Brussels: International Diabetes Federation; 2015. p. 11-129.

7. Shen J, Kondal D, Rubinstein A, Irazola V, Gutierrez L, Miranda JJ, et al. A multiethnic study of pre-diabetes and diabetes in LMIC. Glob Heart. 2016;11(1):61-70. https://doi.org/10.1016/j.gheart.2015.12.015.

8. Gomez-Arbelaez D, Sánchez-Vallejo G, Perez M, Garcia RG, Arguello JF, Peñaherrera $E$, et al. Hyperglycaemia is associated with worse outcomes in Latin-American individuals with acute myocardial infarction. Clin Invest Arterioscler. 2016;28:9-18. https://doi.org/10.1016/j.arteri.2015.09.003.

9. Tseng E, Greer RC, O'Rourke P, Yeh HC, McGuire MM, Clark JM, et al. Survey of primary care providers knowledge of screening for diagnosing and managing prediabetes. J Gen Intern Med. 2017;32(11):1172-8. https://doi. org/10.1007/s11606-017-4103-1.

10. American Diabetes Association. Standards of medical care in diabetes-2016. Diabetes Care. 2016;39(Suppl 1):S1-2. https://doi.org/10.2337/ dc16-S00.

11. Bamberg F, Hetterich $H$, Rospleszcz S, Lorbeer R, Auweter SD, Schlett CL, et al. A subclinical disease burden as assessed by whole-body MRI in subjects with prediabetes, subjects with diabetes, and normal control subjects from the general population: the KORA-MRI study. Diabetes. 2017;66(1):158-69. https://doi.org/10.2337/db16-0630.

12. Moss EL, Tobin LN, Campbell TS, Von Ranson KM. Behavioral weightloss treatment plus motivational interviewing versus attention control: lessons learned from a randomized controlled trial. Trials. 2017;18(1):351. https://doi.org/10.1186/s13063-017-2094-1.

13. Barry E, Roberts S, Oke J, Vijayaraghavan S, Normasenll R, Greenhalgh T. Efficacy and effectiveness of screen and treat policies in prevention of type 2 diabetes: systematic review and meta-analysis of screening tests and interventions. BMJ. 2017;356:16538. https://doi.org/10.1136/bmj. i6538.

14. López-Jaramillo P, Calderón C, Castillo J, Escobar ID, Melgarejo E, Parra GA. Prediabetes in Colombia: expert consensus. Colomb Med. 2017;48:191203. https://doi.org/10.25100/cm.v43i4.3662.

15. Knowler WC, Barrett-Connor E, Fowler SE, Hamman RF, Lachin JM, Walker EA, et al. Reduction in the incidence of type 2 diabetes with lifestyle intervention or metformin. N Engl J Med. 2002;346:393-403. https://doi. org/10.1056/NEJMoa012512.

16. Diabetes Prevention Program Research Group. Long-term safety, tolerability, and weight loss associated with metformin in the Diabetes Prevention Program Outcomes Study. Diabetes Care. 2012;35:731-7. https:// doi.org/10.2337/dc11-1299.

17. Diabetes Prevention Program Research Group. Long-term effects of lifestyle intervention or metformin on diabetes development and microvascular complications over 15-year follow-up: the Diabetes Prevention Program Outcomes Study. Lancet Diabetes Endocrinol. 2015;3(11):86675. https://doi.org/10.1016/S2213-8587(15)00291-0.

18. Ramachandran A, Snehalatha C, Mary S, Mukesh B, Bhaskar AD, Vijay V, et al. The Indian Diabetes Prevention Programme shows that lifestyle modification and metformin prevent type 2 diabetes in Asian Indian subjects with impaired glucose tolerance (IDPP-1). Diabetologia. 2006:49:289-97. https://doi.org/10.1007/s00125-005-0097-z.

19. Lindström J, Ilanne-Parikka P, Peltonen M, Aunola S, Eriksson JG, Hemio K, et al. Sustained reduction in the incidence of type 2 diabetes by lifestyle intervention: follow-up of the Finnish Diabetes Prevention Study. Lancet. 2006;368:1673-9. https://doi.org/10.1016/S0140-6736(06)69701-8. 
20. Holman RR, Paul SK, Bethel MA, Matthews DR, Neil HA. 10-year followup of intensive glucose control in type 2 diabetes. N Engl J Med. 2008;359:1577-89. https://doi.org/10.1056/NEJMoa0806470.

21. Ruiz F, Arias JF, Barragan M, Lopez A, Ariza JF, Cruz CM, et al. Política de atención integral en salud. Ministerio de Salud y Protección Social:"Un sistema de salud al servicio de la gente.". Bogota: Ministerio de Salud y Protección Social; 2016

22. Organization Pan American Health. Medical training oriented to primary care. Geneva: World Health Organization; 2010.

23. World Health Organization. Global action plan for the prevention and control of noncommunicable diseases 2013-2020. Geneva: World Health Organization; 2013. p. 5-102.
24. Schwalm JD, McCready T, Lopez-Jaramillo P, Yusoff K, Attaran A, Lamelas $P$, et al. A community-based comprehensive intervention to reduce cardiovascular risk in hypertension (HOPE 4): a cluster-randomised controlled trial. Lancet. 2019; 394:1231-42. https://doi.org/10.1016/s0140 $-6736(19) 31949-x$.

\section{Publisher's Note}

Springer Nature remains neutral with regard to jurisdictional claims in published maps and institutional affiliations.
Ready to submit your research? Choose BMC and benefit from:

- fast, convenient online submission

- thorough peer review by experienced researchers in your field

- rapid publication on acceptance

- support for research data, including large and complex data types

- gold Open Access which fosters wider collaboration and increased citations

- maximum visibility for your research: over 100M website views per year

At BMC, research is always in progress.

Learn more biomedcentral.com/submissions 